\title{
Establishment of a closed artificial ecosystem to ensure human long-term survival on the
}

\section{moon}

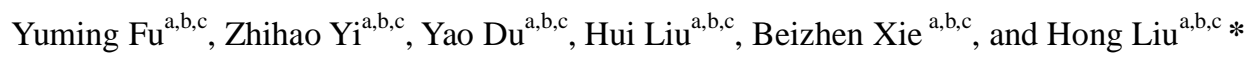

${ }^{a}$ Beijing Advanced Innovation Centre for Biomedical Engineering, Beihang University, Beijing, 100083, China

${ }^{\mathrm{b}}$ School of Biological Science and Medical Engineering, Beihang University, Beijing, 100083, China

${ }^{\mathrm{c}}$ International Joint Research Center of Aerospace Biotechnology \& Medical Engineering, Beihang University, Beijing 100083, China

\section{*Corresponding author:}

Hong Liu, Ph.D, Professor

Beihang University,

Phone numbers: +8610 82339837

E-mail: LH64@buaa.edu.cn 
Abstract: Bioregenerative life support system (BLSS) is a critical technology maintaining long-term human survival on the Moon or other extraterrestrial bodies. In the current study, we carried out a 370-day integrated high-closure experiment (“Lunar Palace 365” experiment) on the Earth in an upgraded ground-based BLSS experimental facility called "Lunar Palace 1". This experiment was designed to develop techniques to run and adjust system stability under long-term operation and crew shift change conditions. Eight volunteering crew members were divided into two groups with three time phases: Group I stayed in the cabin for the initial 60-day phase; Group II inhabited the cabin instead for a record-breaking duration of 200 days as the second phase; Group I re-entered the cabin, replaced Group II and stayed for the last 105 days. Our results demonstrated the BLSS had excellent stability with a material closure degree of $98.2 \%$. Levels of $\mathrm{O}_{2}, \mathrm{CO}_{2}$ and trace harmful gases were well controlled within ranges optimal for crew health and plant production. The system exhibited a strong robustness and could quickly minimize effects of disturbances through self-feedback adjustments. The efficiency of plant production completely met the crew's need of plant-based food. The purification efficiency of domestic and sanitary wastewater was up to irrigation standards, and the recovery rate of urine and solid waste achieved $99.7 \%$ and $67 \%$, respectively. These results are valuable for further optimization of the BLSS in a lunar base and computer simulations of similar systems.

Keywords: Ecosystem ecology, bioregenerative life support system (BLSS), lunar base, atmospheric stability, material circulation

\section{Introduction}

Space science is developing vigorously, especially regarding manned landing on the Moon. Long-term lunar bases will be established in the near future to better explore the Moon. This requires for more verifications and studies, which also has significance of reference for further Martian explorations. It is a huge challenge to live outside the Earth and thus important to build Bioregenerative Life Support System (BLSS), closed artificial ecosystem based on ecological principles, in which oxygen, water, and major food sources are recycled using biotechnology and 
engineering control technology, creating an Earth-like microenvironment ${ }^{1}$. BLSS is the most advanced life support technology, but also the most complex and highest-priority technology in long-term manned deep space exploration activities such as future, long-term lunar bases ${ }^{2}$. Before advancing into practical space exploration, techniques running and adjusting a steady BLSS must be first developed through simulation experiments on the Earth. This will provide an experimental basis and a data reference for BLSS engineering applicable to lunar bases. To meet this, from the 1970s and '80s to the beginning of 21 st century, several countries, including Russia (BIOS-3 system $^{3}$, the United States (BIO-Plex system $)^{4}$, Japan (CEEF system $)^{5}$ and the European Union (MELLISA system) ${ }^{6}$ have performed crewed simulation experiments of BLSS on the Earth.

In recent years, with the rapid development of manned spaceflight industry, breakthroughs in BLSS unit technologies, particularly the development of highly efficient plant cultivation ${ }^{7-9}$, animal protein production ${ }^{10,11}$, nitrogen recovery from urine ${ }^{12}$, and bioconversion of solid wastes into soil-like substrates ${ }^{13-15}$, have been achieved. Based on the development of BLSS unit technologies, teams from China have carried out research to integrate these technologies into BLSS. In previous studies, much attention was paid to the regeneration of $\mathrm{O}_{2}$ and mass flow in a BLSS. For instance, microalgae and lettuce had been shown as meeting the $\mathrm{O}_{2}$ demand of $1 / 2$ of people in 297 days of closed experiments ${ }^{16}$; Azolla photosynthetic $\mathrm{O}_{2}$ release was able to achieve $\mathrm{O}_{2}-\mathrm{CO}_{2}$ homeostasis in the "Azolla-fish-men" closed system ${ }^{8}$, while a $13.5 \mathrm{~m}^{2}$ planting area met the $\mathrm{O}_{2}$ demand of one person in a two-person, 30-day "lettuce-human" integrated controlled ecological life support system (CELSS) test ${ }^{17}$. More recent studies investigated the regeneration rate of other BLSS components of longer durations and more diverse crew conditions. For example, in 2014, our group carried out the first 105-day integrated experiment in a ground-based BLSS facility, Lunar Palace $1^{2,18}$. In that experiment, we used straw to feed yellow mealworms to provide animal protein for volunteering crew members, achieving $100 \%$ recycling of $\mathrm{O}_{2}$ and water and regenerating most foods, with an overall closure degree of $97 \%$. To explore the establishment of CELSS for future long-term extraterrestrial stays, a four-person and 180-day CELSS integrated experiment was performed by the Astronaut Research and Training Center of China in $2016^{19}$. That study systematically converted the material regeneration model from physical-chemical to biological regeneration, and confirmed the applicability and reliability of each unit's technology. 
Despite the significant progress in BLSS integration research, there is still a need to establish a

BLSS which will function well over long-term continuous operation in an extraterrestrial environment. In addition, when performing long-term space missions, such as exploration of the Moon, shift changes of crew members are inevitable. It is therefore important to understand how a BLSS can run steadily during shift changes which could largely affect the metabolic rate of the system. Impacts of power failures and other equipment malfunction during the operation should also be considered to develop a viable BLSS.

In the current study, we carried out a ground-based 370-day, integrated high-closure experiment ("Lunar Palace 365" experiment) to explore long-term life support needs of a lunar-base-like habitat with multiple crew member shift changes. Such an experiment will improve not only the system closure degree and stability in long-term operations, but also our knowledge of human life support regarding long-term Moon habitation.

\section{Materials and methods}

\subsection{Lunar Palace 1, a ground-based artificial, closed ecological facility}

The "Lunar Palace 365" program to test a life support system for 365 days was carried out in "Lunar Palace 1", a ground-based comprehensive, experimental BLSS facility located in Beihang University (BUAA). Lunar Palace 1 was designed to contain two plant cabins and one comprehensive cabin (Fig. 1), with a total area of $160 \mathrm{~m}^{2}$ and volume of $500 \mathrm{~m}^{3}$. Each plant cabin was divided into two parts (plant cabin I and II) with independent environmental condition control. The plant cabin was critical to the regeneration of $\mathrm{O}_{2}$ and water as well as food production. The comprehensive cabin, the main living space for the volunteer crew members, hosted four one-bed cubicles, a bathroom, an animal-raising room, a living room, a storage room and a waste-treatment room. The whole system was closed and completely air-tight without any material interaction with the outside. The actual gas leakage rate of the cabin at normal pressure was only $0.043 \% / \mathrm{d}^{2,20}$, except for three time points wherein intentionally simulated accidents were carried out. The temperature and humidity in plant cabin I during the whole experiment were $22.25 \pm 1^{\circ} \mathrm{C}$ and 62.09

$\mathbf{\pm 5 . 2 8 \%}$, and $22.72 \pm 0.89^{\circ} \mathrm{C}$ and $61.52 \% \pm 5.11 \%$ for plant cabin II. Temperature and humidity 
control of the plant cabin was stable, and conformed to typical planting conditions ${ }^{2,3,21}$. Temperature and humidity fluctuations of the comprehensive cabin were $24.11 \pm 1.36^{\circ} \mathrm{C}$ and 49.62 $\pm 4.96 \%$, respectively, which met the requirements of the advanced life support system habitation cabin (temperature: $18.5-26.5^{\circ} \mathrm{C}$; relative humidity: $25 \%-70 \%$ ) specified by NASA standards ${ }^{21}$.

\subsection{The biological regeneration cycle of Lunar Palace 1}

Lunar Palace 1 was a BLSS composed of a "human-animal-plant-microorganism" ecosystem, wherein the crew members cultivated food plants, vegetables, and fruits as the crew's food (Fig. 1). The plants absorbed $\mathrm{CO}_{2}$ from the air and generated $\mathrm{O}_{2}$ via photosynthesis, with the $\mathrm{O}_{2}$ used in turn for respiration by the crew, animals, and microorganisms. Thus, regeneration of $\mathrm{O}_{2}$ was realized in the BLSS system, maintaining the gas balance of the system.

Water output of the crew included domestic wastewater and urine (Fig. 2A). Domestic wastewater was transferred to a membrane biological activated carbon bioreactor (MBACR) for purification; the urine of the crew went into rotary evaporation to retrieve elemental nitrogen and water, which was subsequently transferred to the MBACR for purification too. The reclaimed water from the MBACR was transferred into plant nutrient solution preparation tank and then disinfected by UV for plant growth. The irrigation water was purified by evaporation and plant transpiration, and was transited to liquid water in plant cabin condensate. After MBACR purification and UV disinfection, the water was then ready for direct use of the crew, including drinking water, sanitary water and domestic water.

The grain straw was dried and crushed after harvest, the better part of which were mixed with feces of the crew and placed into solid fermentation unit inoculated with a straw decomposition bacterial agent. A small amount of straw was fermented, and another small amount of straw was used to cultivate mushroom. The fermented straw and mushroom substrate were then mixed with the leaves of harvested vegetable plants as feed for insects (yellow mealworms). The feed residue (including insect dung) generated by the insects were also placed into the fermenter. Thus, solid wastes, including crew feces, insect feed residue and straw, were mixed and fermented in the solid fermentation unit. The $\mathrm{CO}_{2}$-rich gas generated by fermentation was purified by air purifiers and then introduced into the plant cabin for photosynthesis. Some of the solid products after 
fermentation were used for plant cultivation, while others were collected, compressed and stored. Yellow mealworms provided some animal protein for the crew. The process of solid waste recycling is shown in Fig. 3A.

\subsection{Plant cultivation}

The plant cabin was a critical component unit. Its internal cultivation device had a three-layer stereoscopic design, with a total planting area of $120 \mathrm{~m}^{2}$. Considering human energy and nutrition requirements ${ }^{22}$, nutrition compositions of plant-based $\operatorname{~food~}^{23}$ and the diversity and richness of food, 35 kinds of plants (including five kinds of food crops, 29 kinds of vegetables and one kind of fruit) were selected, and the corresponding planting zoning design was determined (Table S1).

Based on the light requirement of each plant ${ }^{21}$ and our previous studies ${ }^{2}$, the planting were assigned to the two plant cabins with different light parameters. For plant cabin I, the lighting was continuous (24/0 h light/dark), with the light intensity of 300-800 $\mu \mathrm{mol} \mathrm{m}^{-2} \mathrm{~s}^{-1}$. For plant cabin II, the light cycle was 12/12 h light/dark with light from 08:00 to 20:00 everyday and a light intensity of 250-800 $\mu \mathrm{mol} \mathrm{m} \mathrm{m}^{-2} \mathrm{~s}^{-1}$. Vermiculite or soil-like substrate converted from solid wastes was used for solid media culture in plant cabin I, and hydroponics were used for plant cabin II. Hoagland nutrient solution was used for irrigation in both plant cabins.

\subsection{Experimental design and crew selection}

We also investigated the impact of scenarios that might happen during actual lunar missions, including crew shift changes and simulated accidents, on the stability of the system. Further, effects of different lighting environments (i.e., whether the window was blocked or not) on the crew's emotions and biological rhythms were explored. The timeline of "Lunar Palace 365" experiment is presented in Fig. S1. The experiment has three phases: 1) Group I was on duty at the initial phase of 60 days; 2) Group II then stayed instead in the system for a record-breaking 200 days for the second phase; 3) Group I re-entered the cabin to replace Group II for the 105-day third phase, with an additional "accidental" five-day extension for the psychological testing of the crew members. In the last month, three simulated power loss accidents for two, three and four hours were conducted. The purpose of the accident scenarios was to assess both the changes in $\mathrm{CO}_{2}$ concentration in the system when the power was accidentally down and the time for the system to recover to a stable state. 
There were crew shift changes between each two adjacent phases of the experiment, which took place on the $60^{\text {th }}$ and the $260^{\text {th }}$ days. In order to prevent any gas exchange between the system and the outside during shift changes, the crew was required to enter the cabin through an airlock chamber (Fig. S2). For each shift change, the incoming crew would first enter the cabin through the airlock chamber at the time of 10:00 and conduct mission handover work in the cabin with the outgoing crew. After seven hours (at 17:00), the first set of volunteers would leave the cabin through the airlock chamber to complete the shift change. During the shift change process, there were a total of eight crew members in the cabin for a long duration of seven hours, serving as an overload disturbance to the system. Throughout the experiment, concentration changes of $\mathrm{O}_{2}$ and $\mathrm{CO}_{2}$ in the system were measured by sensors (FGD10B, Status Scientific Controls Ltd, Status Scientific Controls Ltd, UK) and logged by the control system.

Based on the experimental design, the eight volunteers chosen as crew members of "Lunar Palace 365" were divided into two groups (4 volunteers/each group, including two males and two females). All volunteers were aged 24 to 30 years old and tested as physically and psychologically healthy, without unhealthy habits or serious diseases. Basic characteristics of the volunteers are presented in Table $\mathrm{S} 2$. The respiration- $\mathrm{CO}_{2}$ production rate after moderate labor of crew group II was about 10\% higher than that of crew group I (Fig. S3), suggesting a difference in the metabolic rate of the two crew groups. The labor, including plant cultivation unit maintenance, waste treatment unit maintenance, food harvest and food processing, health index detection etc., were clearly assigned to the four members in each group. Daily working and sleeping hours were both eight hours.

\section{Results and discussion}

\subsection{Atmosphere control}

\subsection{1 $\mathrm{O}_{2}$ and $\mathrm{CO}_{2}$ balance}

Maintaining $\mathrm{O}_{2}$ and $\mathrm{CO}_{2}$ concentrations in an appropriate range is a basic indicator of BLSS stability. Concentrations of $\mathrm{CO}_{2}$ and $\mathrm{O}_{2}$ in the cabin throughout the experiment are shown in Fig. 4A. In the dark phases from 20:00 to 08:00 at the next day in plant cabin II, this cabin was not a producer of $\mathrm{O}_{2}$ but a consumer, and thus the $\mathrm{CO}_{2}$ and $\mathrm{O}_{2}$ concentrations showed daily fluctuations. 
Overall, the $\mathrm{CO}_{2}$ concentration was held between 246-4,131 ppm throughout the experiment, with an average $\mathrm{CO}_{2}$ concentration of $1241 \mathrm{ppm}$. Accordingly, $\mathrm{O}_{2}$ concentration in the system was maintained within $20.11 \%-21.52 \%$, with an average of $20.71 \%$. All these data are very close to the design standards of NASA's latest advanced life support system for the atmospheric environment level of crew requirements $(21.2 \%$ oxygen) and plant requirements (1300 ppm $\left.\mathrm{CO}_{2}\right)^{24}$. In general, for BLSSs, and similar compact closed spaces such as the international space station (ISS), it is essential to avoid possible accumulation of $\mathrm{CO}_{2}$ so as to avoid negative effects on humans and plants. Recent NASA studies have shown that excessive $\mathrm{CO}_{2}$ could lead to headaches and reduce cognitive function of the $\mathrm{crew}^{25,26}$. Furthermore, NASA reduced the maximum allowable $\mathrm{CO}_{2}$ concentration of ISS to $4 \mathrm{mmHg}(5,332 \mathrm{ppm})$, with an evidence that $\mathrm{CO}_{2}$ concentration between $0.5 \mathrm{mmHg}(666 \mathrm{ppm})$ and $2.0 \mathrm{mmHg}(2,667 \mathrm{ppm})$ is optimal to maintain the health and performance of astronauts ${ }^{26,27}$. Our prior studies also demonstrated that, although an appropriate increase in atmospheric $\mathrm{CO}_{2}$ content increased plant yield, this beneficial effect disappeared when $\mathrm{CO}_{2}$ was over 2,000 ppm, while an inhibitory effect to the plant occurred when $\mathrm{CO}_{2}$ levels exceeded 5,000 ppm $^{28,29}$. Compared with the BIOS-3 experiment ${ }^{3}$ of Russia and the 105-day Lunar Palace 1 experiment ${ }^{2}$, dynamic atmospheric data of our current system showed a higher stability in $\mathrm{CO}_{2}$ and $\mathrm{O}_{2}$ concentrations.

In addition to the short-term peak of $\mathrm{CO}_{2}$ gas resulting from the crew shift changes (the $60^{\text {th }}$ and $260^{\text {th }}$ days), there were two longer peaks of $\mathrm{CO}_{2}$ gas fluctuation (61-120 days and 200-260 days), both falling in the second phase of the experiment (group II) (Fig. 4A). Two reasons were attributed to the first long peak (after the $60^{\text {th }}$ day): 1) Unlike rigid physical-chemical systems, Lunar Palace 1 was a biological system with stronger adaptability to changes. Immediately after the crew shift change, the incoming group II had a higher metabolic rate that generated a higher-load impact on the system. Adaptation of the biological system was a slow process, leading to the accumulation of $\mathrm{CO}_{2}$ right after the shift change. 2) When the $\mathrm{CO}_{2}$ exceeded 3,000 ppm, it inhibited plant growth. This further aggravated the accumulation of $\mathrm{CO}_{2}$. The second long peak (after the $260^{\text {th }}$ day) could be attributed the artificial inhibition of wheat growth during the test of the resilience and recovery function of the biological system. Plant unit was the only unit in the system able to regenerate $\mathrm{O}_{2}$, in which wheat occupied the largest planting area in Lunar Palace 1. 
Therefore, inhibition of wheat growth could have a large impact on the gas stability of the system.

The system atmosphere returned to a relatively stable state after two $\mathrm{CO}_{2}$ fluctuation peaks by adjusting photoperiods of plant units ${ }^{2,18,30}$, fermentation rates of waste units ${ }^{31}$ and other biological regulation factors. All these findings verify the elasticity of the biological system and the effectiveness of biological units in regulating atmospheric balance. In addition, the elevated $\mathrm{CO}_{2}$ and the corresponding $\mathrm{O}_{2}$ decreases also verify the airtightness of Lunar Palace 1 system, as shown in Fig. 4A. During shift changes, carbon dioxide rose from its initial stable state and then fell slightly before settling into a new stable state (Fig. 4B \& Fig. 4C), indicating that the system was highly regulated.

When the BLSS power was "accidentally" lost, the plants were unable to photosynthesize due to the dark, while humans and other animals continued to produce $\mathrm{CO}_{2}$. Thus, the concentration of $\mathrm{CO}_{2}$ in the system increased (Fig. 4D). When the initial $\mathrm{CO}_{2}$ concentration in the system was lower than $600 \mathrm{ppm}$, the power loss resulted in an increase of $\mathrm{CO}_{2}$ concentration, which remained below $1,800 \mathrm{ppm}$ at a rate of $251.0-312.3 \mathrm{ppm} / \mathrm{h}$ within four hours. When the power was restored, $\mathrm{CO}_{2}$ returned to a stable state within 12 - 24 hours (Fig. 4D), indicating that atmospheric fluctuations caused by power loss was small enough for the system to quickly adjust. It is possible that the increase in $\mathrm{CO}_{2}$ (to $\sim 2,000 \mathrm{ppm}$ ) improved plant photosynthesis after the power was restored ${ }^{28,29}$, leading to a new $\mathrm{CO}_{2}$ concentration stable state in the system in a short time (Fig. ???). Moreover, increasing $\mathrm{CO}_{2}$ production rate was closely related to the temperature of the system (Fig. 4D \& Fig. 4E), which is consistent with a previous study ${ }^{32}$ pointing out that plant respiration intensity positively correlates with system temperature within a certain temperature range. Importantly, a $100 \%$ recycling rate of $\mathrm{O}_{2}$ was achieved without any external gas input.

\subsubsection{Trace harmful gases}

During the 370-day airtight experiment, 12 trace harmful gases, including hydrogen sulfide, were tested periodically. Concentrations of these gases were all controlled within a certain range (Fig. S4). We compared these data with the allowable concentration of air composition in a Chinese nuclear submarine cabin (GJB11A-98), the maximum allowable concentration of harmful gases in NASA manned spacecraft (JSC20584), and the maximum allowable concentration of harmful gas 
in Russian manned spacecraft (ГОCT P50804-95) (Table S3). We found that the highest concentrations of harmful gases in our experiment were far below the maximum allowable concentrations of the Chinese standards, and only the concentrations of acrolein and ozone were slightly higher than those allowed by NASA and Russia ${ }^{33-35}$. We expect that acrolein was a trace gas readily produced by the decomposition of food and condiments in the cooking process, while the trace ozone may have been produced by the ultraviolet light source. Taken together, these results indicate that the BLSS can effectively control the concentrations of trace harmful gases by air purification of the plant unit, thus providing the crew with a healthy living and working environment. These results also support previous findings that there was no continuous accumulation of trace harmful gases in closed ecosystems due to the absorption and removal of biological units ${ }^{3}$.

\subsection{Food production}

Table S4 shows the production efficiency of crops during the "Lunar Palace 365" experiment.

Crop yields were all greater compared with those in the "Lunar Palace 105" experiment ${ }^{2}$. However, compared with the BIOS-3 system in Russia ${ }^{36}$ and the NASA basic value of advanced life support system in the United States (ALS-BVAD) ${ }^{21}$, some crops in our experiment exhibited lower yields. The reason might be that there are differences in crop varieties, which means that more productive crop varieties that are suitable for growing in closed artificial ecosystem need to be developed.

The food regeneration rate in the system, calculated in dry weight, was $73 \%$ throughout the experiment (Fig. S5). In fresh weight, the regeneration rate was $83 \%$ instead, with a $100 \%$ plant-based food regeneration rate. The food regeneration rate in dry weight $(73 \%)$ in the current four-person 370-day experiment was higher than that in a previous three-person 105-day closed experiment $(55 \%)^{2}$, a four-person 180-day closed experiment $(55 \%)^{19}$, and the three-person 90-day BIOS-3 experiment in Russia (48\%) ${ }^{3}$, but lower than that in the Japanese two-person 28-day CEEF system experiment $(92 \%-95 \%)^{37}$. It is important to note that the food regeneration capacity of a system not only depends on the crew size, but also relies on the planting area size of crops. Compared with the larger planting area in the other systems, such as the four-person, 180-day closed experiment system $\left(260 \mathrm{~m}^{2}\right)$ and the Japanese two-person 28-day CEEF system $\left(150 \mathrm{~m}^{2}\right)$, the planting area of our present experiment was only $120 \mathrm{~m}^{2}$. Therefore, our experiment 
exhibited a relatively lower resource consumption.

\subsection{Water recovery}

Fig. 2B shows the details of the water utilization and regeneration in the experimental system of "Lunar Palace 365". Water consumption of each crew group was $74.37 \mathrm{~kg} / \mathrm{d}$, and daily water consumption of each crew member was $18.59 \mathrm{~kg}$ person ${ }^{-1}$ day $^{-1}$. These values fall between the designed water demand of an early planet base and a mature planet base $\mathrm{e}^{21}$. Total transpiration of the plant cabin was $724.26 \mathrm{~L} / \mathrm{d}$, and the average transpiration rate over the $120 \mathrm{~m}^{2}$ planting area was $6.13 \mathrm{~L} \mathrm{~m}^{-2}$ day $^{-1}$, which is similar to that obtained in previous reports ${ }^{5,38}$. Condensed water generated by the system after purification and boiling was in line with the drinking water standards of China, the United States, and Russia (Table S5). Reclaimed water from wastewater purification conformed to the standards for hydroponics water for agricultural irrigation (Table S6) and was directly used as nutrient solution for plant irrigation. There was no external water input during the entire experiment, with a $100 \%$ recycling of water.

\subsection{Solid waste bioconversion}

The logistics of waste treatment and recycling in the "Lunar Palace 365" experiment is presented in Fig. 5. In this experiment, urine and fresh feces produced by each crew group per day were 7,130 g and $779 \mathrm{~g}$ (about $198 \mathrm{~g}$ of dry weight), respectively. Daily metabolic waste per person was $1,783 \mathrm{~g}$ of urine and $195 \mathrm{~g}$ of fresh feces. The mass of urine and feces varies with the quantity and composition of consumed food and drinking water ${ }^{21}$. The urine amount in the current experiment were within the range observed by NASA $\left(1,390-2,107 \mathrm{~g} \mathrm{person}^{-1}\right.$ day $\left.^{-1}\right)$ in previous studies ${ }^{21}$, but the feces were slightly more than those measured by NASA (20.5-132.0 $\left.\mathrm{g}_{\text {person }}{ }^{-1} \mathrm{day}^{-1}\right)$. This may be because the diet of the crew in the current experiment had more abundant fiber and additional fiber in the diet was known to increase daily stool mass ${ }^{39}$.

The urine was distilled under low pressure after biological pretreatment, recovering 7,110 $\mathrm{g}$ water with a $99.7 \%$ recovery of nitrogen (Fig. 5). The residual urine slag was stored (Fig. 2A). The recovered water was further treated to prepare nutrient solutions for plant irrigation (Fig. 2A). Compared with the previous 105-day "Lunar Palace 105" experiment ${ }^{2}$, the ability of the current system to treat the urine increased by 1.22 -fold (increased from 3,295 to 7,130 g/d). This ensured the requirement of irrigation water for plants and further ensured the amount of drinking water for 
crew.

Feces produced daily by the crew, together with non-edible biomass of plants and yellow mealworm feed residue (vegetable old leaf and insect dung) were fermented. The total, cumulative dry weights of straw, human feces, and yellow mealworm feed residue were 151,129 g (including the initial 3,000 g), 73,233 g, and 10,403 g, respectively, during the 370-day experiment. At the end of the experiment, the dry weight of remaining fermentation material in the solid waste fermentation device was 7,826 g. Therefore, the waste degradation rate of the solid waste fermentation unit was $67 \%$, with the microbes degrading $400 \mathrm{~g}$ of dry solid waste on average per day. The key role of microbial degradation in the waste treatment was to make element carbon in the waste enter the atmosphere to rejoin the material cycle. Based on changes in carbon content before and after fermentation, the solid waste fermentation device contributed $670 \mathrm{~g} \mathrm{of} \mathrm{CO}_{2}$ to the atmosphere per day, being an essential part of the material cycle. The solid waste degradation rate of $67 \%$ in the current experiment was a significant improvement upon the rate of $41 \%$ in the "Lunar Palace 105" experiment also taken place in the facility of Lunar Palace $1^{2}$. Additionally, daily solid waste degraded by microorganisms was increased by $259 \mathrm{~g}$ compared to the "Lunar Palace 105" experiment. This demonstrates the performance of the solid waste treatment unit in the current Lunar Palace 1 system. It is worth noting that oxygen consumption of exogenous input must be considered in the calculation of solid waste treatment capacity of the system. To maintain the mass were balanced and stable in BLSS with exogenous input food and condiments for crew, and the equal amount of waste needed to be exported outside the system, which can prevent the accumulation of elements and substances that can cause the system to become unbalanced. Hence, the system optimization should not be based solely on improving the recycling rate of waste such as inedible plant parts and passengers' excrement ${ }^{2}$. The design of each unit of BLSS and the setting of parameters must be considered from the perspective of the whole system, so that each biological unit in the system and the cabin environment can match each other, and the scientific rationality of the overall design cannot be ignored only in pursuit of individual technical indicators .

\subsection{Energy expenditure and health status of the crew}

Through accelerometers worn by crew members, daily energy consumption of each member was 
continuously monitored during the experiment (Fig. S6). Average energy consumption was 2,200 to 2,600 kcal per day for males, and 1,400 to $1,800 \mathrm{kcal}$ for females. These data are similar to that obtained in the 105-day three-person "Lunar Palace 105" experiment ${ }^{2}$. However, the energy consumption of males was slightly higher than that in the CEEF experiment in Japan (1900-2300 $\mathrm{kcal} / \mathrm{d})^{37}$. Human basal energy consumption (BEE) had three components: resting metabolism (basal metabolic), physical activity, and the thermic effect of food ${ }^{40}$. In our study, the crew's composition ratio of the three nutrient classes (protein : carbohydrate $:$ fat $=15: 6: 25$ ) was similar to Japanese CEEF, indicating no significant difference in the thermal effect of food between the two experiments. Therefore, the difference in the energy consumption between Lunar Palace 365 and CEEF were likely due to differences in crew's resting metabolism and physical activity. Moreover, the median energy consumption per person in group I and group II were about 7500 and $8400 \mathrm{kcal}$, respectively. The total energy consumption of crew group II was about $112 \%$ of that of group I, which also confirmed the correctness of the difference in metabolic levels between the two groups designed in this experiment.

In order to ensure the energy supply to the crew, we provided food supplies of $7800 \mathrm{kcal}$ and $8700 \mathrm{kcal}$ per day to groups I and II, respectively, throughout the experiment. The crew's mental and physical health indices did not fluctuate significantly. Also, according to the physical examination results before and after the experiment, all crew members maintained a healthy status $^{41}$.

\subsection{System material closure coefficient}

The proportion of recycled substances in the total substances is presented in Fig. 6. Based on the formula of "closure",2,3, the "Lunar Palace 365" experiment achieved a 100\% recycling regeneration of $\mathrm{O}_{2}$ and water for life support of the crew members, $99.7 \%$ recovery rate of urine, $67 \%$ recovery rate of solid waste, $73 \%$ of the dry weight regeneration of food, and $98.2 \%$ of the system closure degree. The closure of the system was dramatically improved in contrast to the 105-day experiment of Lunar Palace 1.

\section{Conclusion}


The current study demonstrated that the atmosphere of the BLSS showed good stability under a multi-person load (4 persons) and long-term operation (370 days). The selected 35 plants grew well and exhibited high production efficiencies in the system. Water purification for personal hygiene and laundry reached the irrigation standard, and the purified potable water met the standards for condensate water. System closure degree was $98.2 \%$. Those supported the feasibility and functional reliability of the Lunar Palace 1 system for long-term operation. Compared with our previous 105-day experiment, the current system demonstrated the ability to respond to increased $\mathrm{CO}_{2}$ caused by power loss and to quickly recover to a normal level. Moreover, disturbances in atmospheric $\mathrm{CO}_{2}$ concentration caused by shift changes was successfully eliminated by biological regulation, suggesting a good robustness of the system. The data also indicate that the advanced technology of a BLSS with an artificial, closed human-animal-plant-microorganism ecosystem had been achieved. For future work, quantitative research will be carried out in detail to better understand the impact of metabolic differences among crew members, shift change of members, and additional simulated accidents on the stability of the system. Computer simulated models should also be carried out using the data obtained from the current experiment to guide optimization of the BLSS system for practical application.

\section{Acknowledgments}

This work was financially supported by the Pre-research Programme on Manned Spaceflight (PR China, No. 020302).

\section{Conflict of interest}

The authors declare that they have no conflict of interest.

\section{Author contributions}

Hong Liu and Yuming Fu designed the experiments. Zhihao Yi and Hui Liu performed the experiments. Yuming Fu, Zhihao Yi, Yao Du and Beizhen Xie analyzed the data. Yuming Fu, Zhihao Yi, Yao Du and Hong Liu wrote the manuscript. All authors reviewed the manuscript. All authors read and approved the final manuscript. 


\section{Figure legends}

Fig.1 The layout, schematic and future application of Lunar Palace 1

Fig.2 The water cycle and food Production. (A) BLSS water circulation and treatment processes in the "Lunar

Palace 365" experiment. (B) Water consumption and recovery (kg/d) during the "Lunar Palace 365" experiment.

(C) Production efficiency of 13 selected crops $\left(\mathrm{g} \mathrm{m}^{-2} \mathrm{day}^{-1}\right.$, dry weight) in the "Lunar Palace 365 " experiment.

Fig.3 Solid waste processing. (A) Solid waste recycling processes in Lunar Palace 1. (B) The dry weight of solid waste in the "Lunar Palace 365" experiment.

Fig.4 $\mathrm{O}_{2}$ and $\mathrm{CO}_{2}$ fluctuations. (A) The levels of $\mathrm{CO}_{2}$ and $\mathrm{O}_{2}$ over the course of the entire "Lunar Palace $365 "$ experiment (370 days). (B) The change in carbon dioxide concentration around the first crew shift change (28h).

(C) The change in carbon dioxide concentration around the second crew shift change (24h). (D) The changes in

$\mathrm{CO}_{2}$ concentration in the simulated power loss experiments in the Lunar Palace 1. (E) The changes in temperature in the simulated power loss experiments in the Lunar Palace 1.

Fig.5 Mass flow relationships among system components in the "Lunar Palace 365" experiment (g/d). Arrows indicate the flow direction of mass. Object boxes represent each biological unit. The yellow, light green and blue dotted frames represent plant cabin I, plant cabin II and water treatment units. Storage waste matter, liquid, gas and food flows are marked by black, blue, purple and red arrows, respectively. The green and yellow arrows represent the cycle of solid matter. Data of solid matter was on a dry-weight basis.

Fig.6 The proportion of recycled substances in the total substances. 


\section{References}

1 Liu, H. et al. A conceptual configuration of the lunar base bioregenerative life support system including soil-like substrate for growing plants. Advances in Space Research 42, 1080-1088 (2008).

Fu, Y. et al. How to establish a Bioregenerative Life Support System for long-term crewed missions to the Moon or Mars. Astrobiology 16, 925-936 (2016).

3 Gitelson, J. I. \& Lisovsky, G. M. Man-made closed ecological systems. Vol. 9 (Crc Press, 2002).

4 Nelson, M., Pechurkin, N. S., Allen, J. P., Somova, L. A. \& Gitelson, J. I. in Environmental Biotechnology. 517-565 (Springer, 2010).

5 Tako, Y. et al. One-week habitation of two humans in an airtight facility with two goats and 23 crops-Analysis of carbon, oxygen, and water circulation. Advances in Space Research 41, 714-724 (2008).

Häder, D.-P., Braun, M. \& Hemmersbach, R. in Gravitational Biology I

113-122 (Springer, 2018).

Dong, C., Fu, Y., Liu, G. \& Liu, H. Growth, photosynthetic characteristics, antioxidant capacity and biomass yield and quality of wheat (Triticum aestivum L.) exposed to LED light sources with different spectra combinations. Journal of agronomy and crop science 200, 219-230 (2014).

Chen, M., Deng, S., Yang, Y., Huang, Y. \& Liu, C. Efficacy of oxygen-supplying capacity of Azolla in a controlled life support system. Advances in space research 49, 487-492 (2012).

Shen, Y., Guo, S., Ai, W. \& Tang, Y. Effects of illuminants and illumination time on lettuce growth, yield and nutritional quality in a controlled environment. Life Sciences in Space Research 2, 38-42 (2014).

Li, L., Zhao, Z. \& Liu, H. Feasibility of feeding yellow mealworm (Tenebrio molitor L.) in bioregenerative life support systems as a source of animal protein for humans. Acta Astronautica 92, 103-109 (2013).

Yu, X., Liu, H. \& Tong, L. Feeding scenario of the silkworm Bombyx Mori, L. in the BLSS. Acta Astronautica 63, 1086-1092 (2008).

Deng, S., Xie, B. \& Liu, H. The recycle of water and nitrogen from urine in bioregenerative life support system. Acta Astronautica 123, 86-90 (2016).

Guo, S., Ai, W., Hou, W. \& Shi, W. Feasibility of the use of degraded inedible biomass of plants as a nutrient liquid for hydroponic cultivation. Hang tian yi хие уи yi хие gong cheng= Space medicine \& medical engineering 14, 360 (2001).

Yu, C. et al. Bioconversion of rice straw into a soil-like substrate. Acta Astronautica 63, 1037-1042 (2008).

He, W., Liu, H., Xing, Y. \& Jones, S. B. Comparison of three soil-like substrate production techniques for a bioregenerative life support system. Advances in space research 46, 1156-1161 (2010).

Tong, L. et al. Gas exchange between humans and multibiological life support system. Ecological Engineering 37, 2025-2034 (2011). CELSS test. Acta Astronautica 100, 140-146 (2014).

8

Dong, C., Fu, Y., Xie, B., Wang, M. \& Liu, H. Element cycling and energy flux responses in ecosystem simulations conducted at the Chinese Lunar Palace-1. Astrobiology 17, 78-86 (2017).

Guo, S., Mao, R., Zhang, L., Tang, Y. \& Li, Y. Progress and prospect of research on controlled ecological life support technique. Reach 6, 1-10 (2017).

HU, D., FU, Y., DU, X., ZHANG, J. \& LIU, H. Evaluation on Gas Tightness of Ground-based 
Experimental Bioregenerative Life Support System. Manned Spaceflight, 23 (2016).

Hanford, A. J. Advanced life support baseline values and assumptions document. Technical Reports, 3 (2006).

Hu, E., Bartsev, S. I. \& Liu, H. Conceptual design of a bioregenerative life support system containing crops and silkworms. Advances in Space Research 45, 929-939 (2010).

Yang, Y., Wang, G. \& Pan, X. China food composition. Peking University Medical Press, Beijing 329 (2002).

Anderson, M. S., Ewert, M. K. \& Keener, J. F. Life support baseline values and assumptions document. (2018).

Law, J., Watkins, S. \& Alexander, D. In-flight carbon dioxide exposures and related symptoms: Association, susceptibility, and operational implications. NASA Technical Paper 216126, 2010 (2010).

Ryder, V. et al. Effects of acute exposures to carbon dioxide upon cognitive functions. (2017).

Law, J. \& Alexander, D. CO2 on the International Space Station: An Operations Update. (2016).

Fu, Y. et al. Unexpected decrease in yield and antioxidants in vegetable at very high CO 2 levels. Environmental chemistry letters 13, 473-479 (2015).

Wang, M. et al. Effects of different elevated CO 2 concentrations on chlorophyll contents, gas exchange, water use efficiency, and PSII activity on C 3 and C 4 cereal crops in a closed artificial ecosystem. Photosynthesis research 126, 351-362 (2015).

Wheeler, R. M. et al. Gas exchange rates of potato stands for bioregenerative life support. Advances in Space Research 41, 798-806 (2008).

1 Liu, G. et al. The regulation of $\mathrm{CO} 2$ levels in a BLSS by controlling the solid waste treatment unit. Ecological Engineering 90, 382-386 (2016).

Morison, J. \& Lawlor, D. Interactions between increasing CO2 concentration and temperature on plant growth. Plant, Cell \& Environment 22, 659-682 (1999).

Fengtao, G., Zhongquan, L. \& Guogen, C. Revision of Allowable Concentrations of Atmospheric Components in Nuclear Submarines (MAC GJB11-84). JOURNAL OF NAVY MEDICINE, 7 (1999).

James, J. T. Spacecraft maximum allowable concentrations for airborne contaminants. (2008).

GOST, R. (Russ).

Salisbury, F. B., Gitelson, J. I. \& Lisovsky, G. M. Bios-3: Siberian experiments in bioregenerative life support. BioScience 47, 575-585 (1997).

Tako, Y. et al. CEEF: closed ecology experiment facilities. Gravitational and Space Research 23 (2010).

Wheeler, R. et al. Crop productivities and radiation use efficiencies for bioregenerative life support. Advances in Space Research 41, 706-713 (2008).

Fu, Y., Guo, R. \& Liu, H. An optimized $4 \square$ day diet meal plan for 'Lunar Palace 1'. Journal of the Science of Food and Agriculture 99, 696-702 (2019).

Nelson, K. M. et al. Effect of weight reduction on resting energy expenditure, substrate utilization, and the thermic effect of food in moderately obese women. The American journal of clinical nutrition $\mathbf{5 5}$, 924-933 (1992).

Hao, Z. et al. Effects of long term isolation on the emotion change of "Lunar Palace 365" crewmembers. Sci Bull 64, 881-884 (2019). 
bioRxiv preprint doi: https://doi.org/10.1101/2021.01.12.426282; this version posted January 14,2021 . The copyright holder for this preprint (which was not certified by peer review) is the author/funder, who has granted bioRxiv a license to display the preprint in perpetuity. It is made available under aCC-BY-NC-ND 4.0 International license.

\section{Figures}

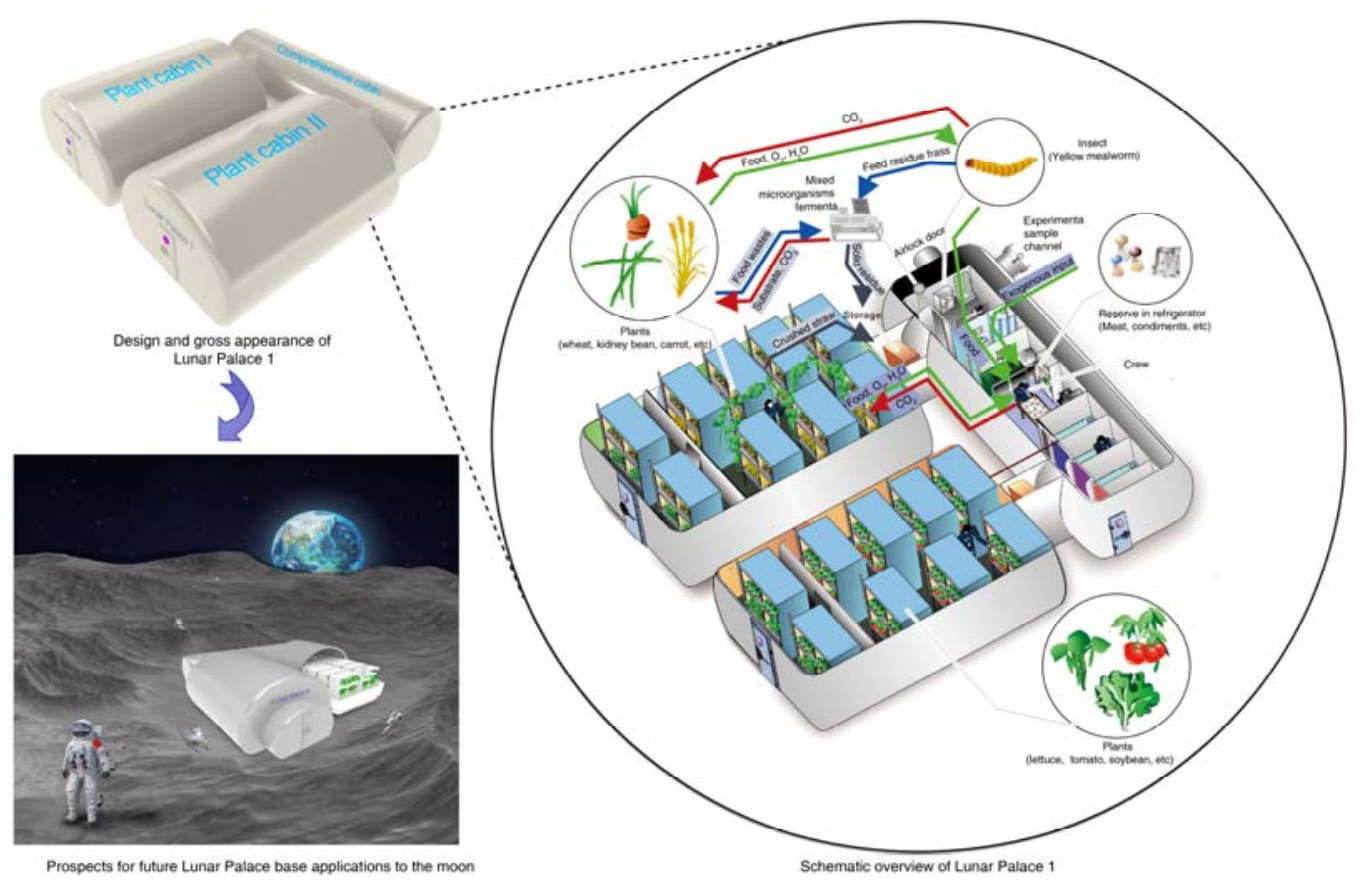

Fig. 1 The layout, schematic and future application of Lunar Palace 1 

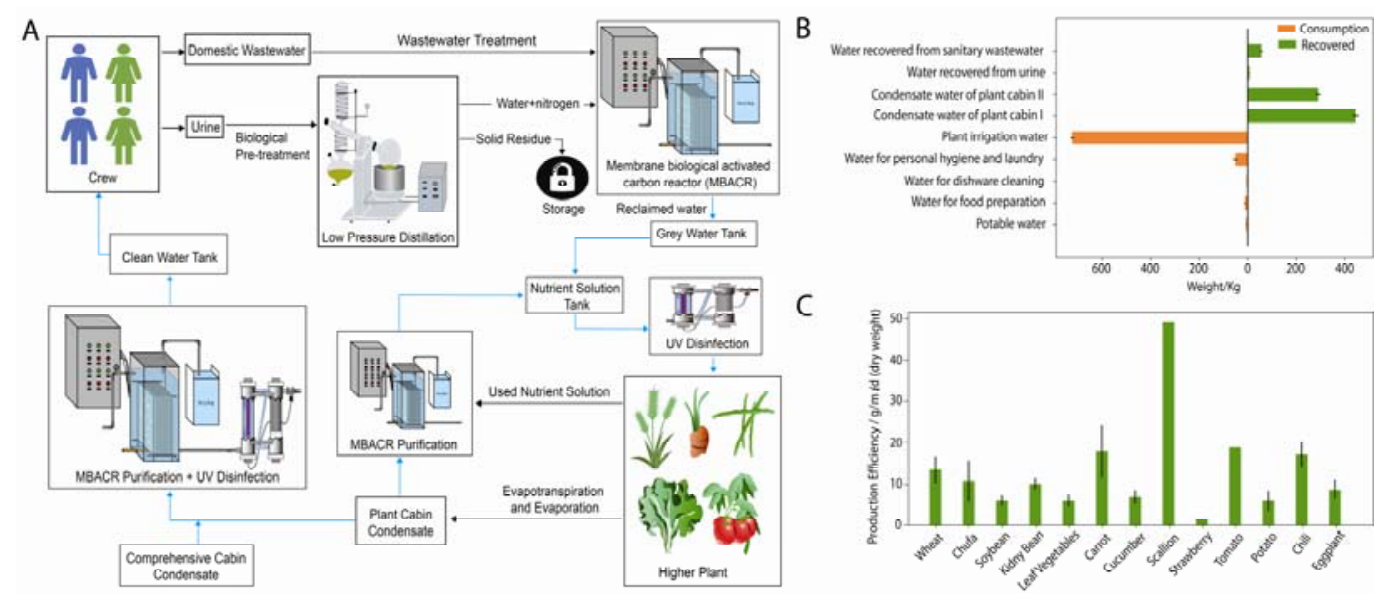

Fig. 2 The water cycle and food Production. (A) BLSS water circulation and treatment processes in the Lunar Palace 365 experiment. (B) Water consumption and recovery $(\mathrm{kg} / \mathrm{d})$ during the Lunar Palace 365 experiment. (C) Production efficiency of 13 selected crops $\left(\mathrm{g} / \mathrm{m}^{2} / \mathrm{d}\right.$, dry weight) in the Lunar Palace 365 experiment. 
bioRxiv preprint doi: https://doi.org/10.1101/2021.01.12.426282; this version posted January 14, 2021. The copyright holder for this preprint (which was not certified by peer review) is the author/funder, who has granted bioRxiv a license to display the preprint in perpetuity. It is made available under aCC-BY-NC-ND 4.0 International license.
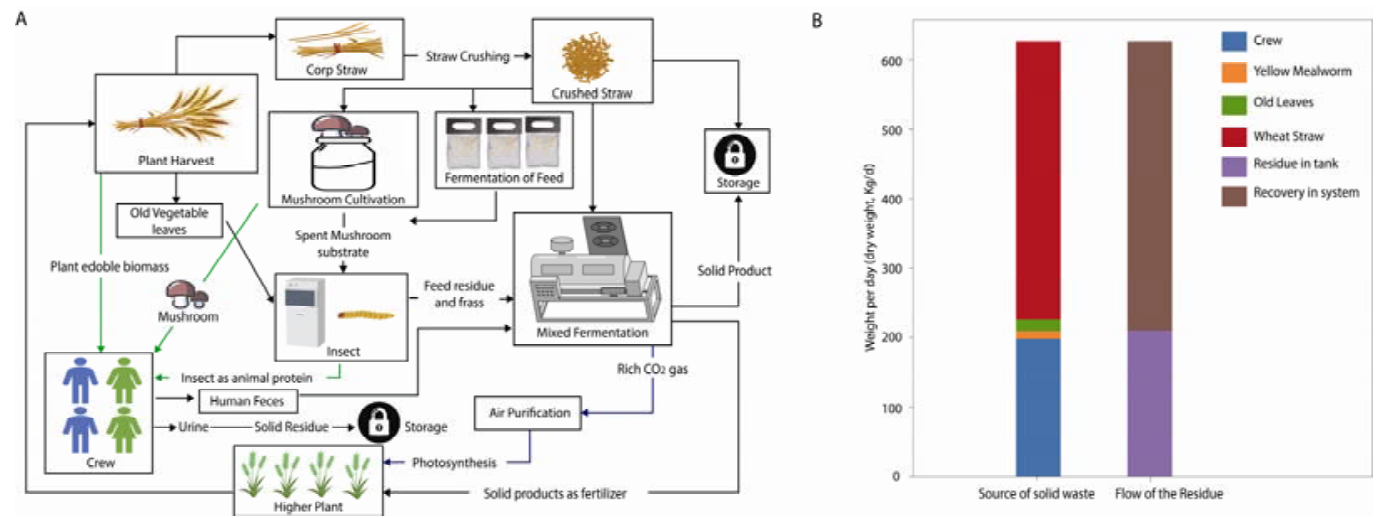

Fig. 3 Solid waste processing. (A) Solid waste recycling processes in Lunar Palace 1.

(B) The dry weight of solid waste in the Lunar Palace 365 experiment. 

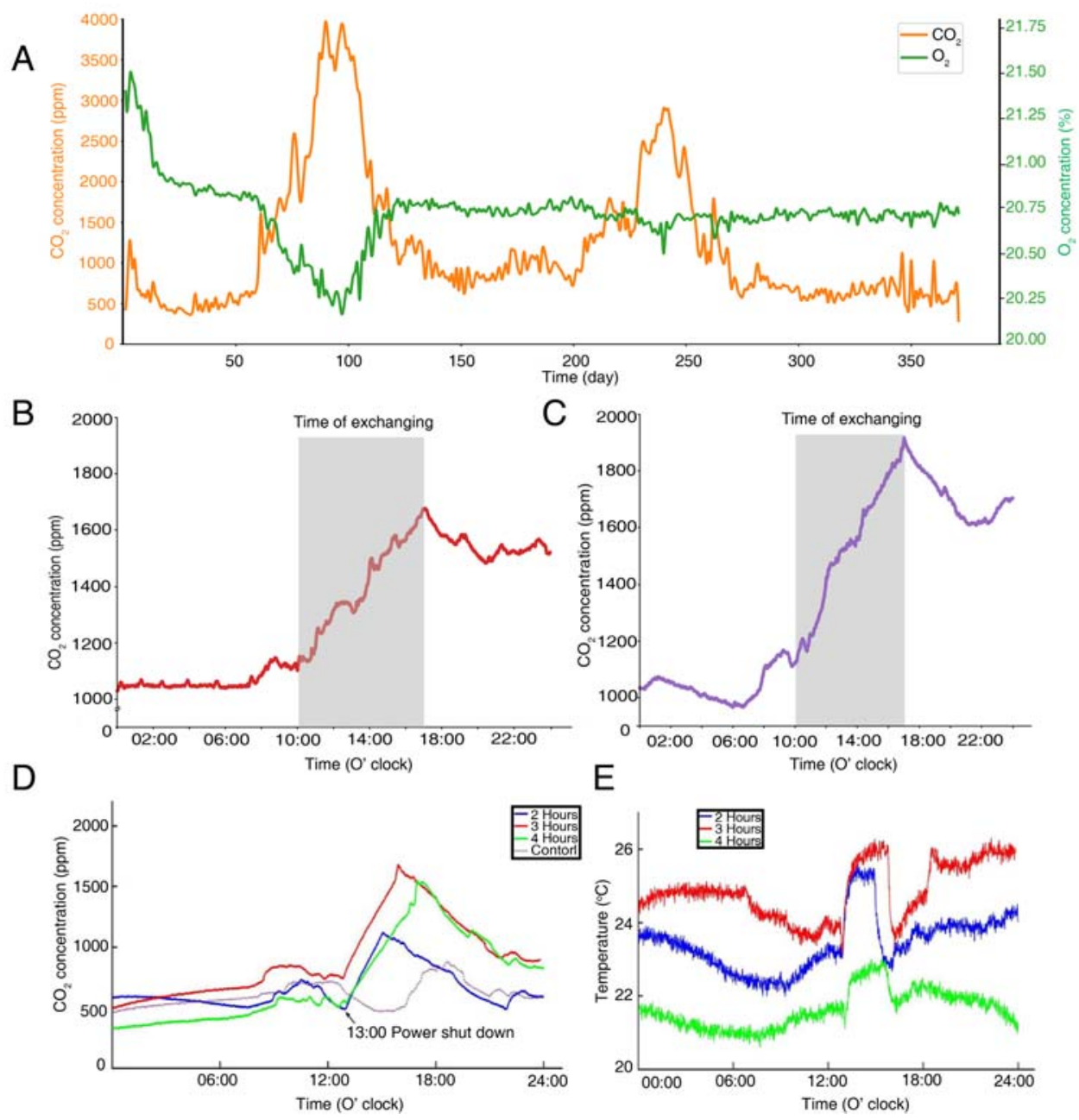

Fig. $4 \mathrm{O}_{2}$ and $\mathrm{CO}_{2}$ fluctuations. (A) The levels of $\mathrm{CO}_{2}$ and $\mathrm{O}_{2}$ over the course of the entire Lunar Palace 365 experiment (370 days). (B) The change in carbon dioxide concentration around the first crew shift change (28h). (C) The change in carbon dioxide concentration around the second crew shift change (24h). (D) The changes in $\mathrm{CO}_{2}$ concentration in the simulated power loss experiments in the Lunar Palace 1. (E) The changes in temperature in the simulated power loss experiments in the Lunar Palace 1. 
bioRxiv preprint doi: https://doi.org/10.1101/2021.01.12.426282; this version posted January 14,2021 . The copyright holder for this preprint (which was not certified by peer review) is the author/funder, who has granted bioRxiv a license to display the preprint in perpetuity. It is made available under aCC-BY-NC-ND 4.0 International license.

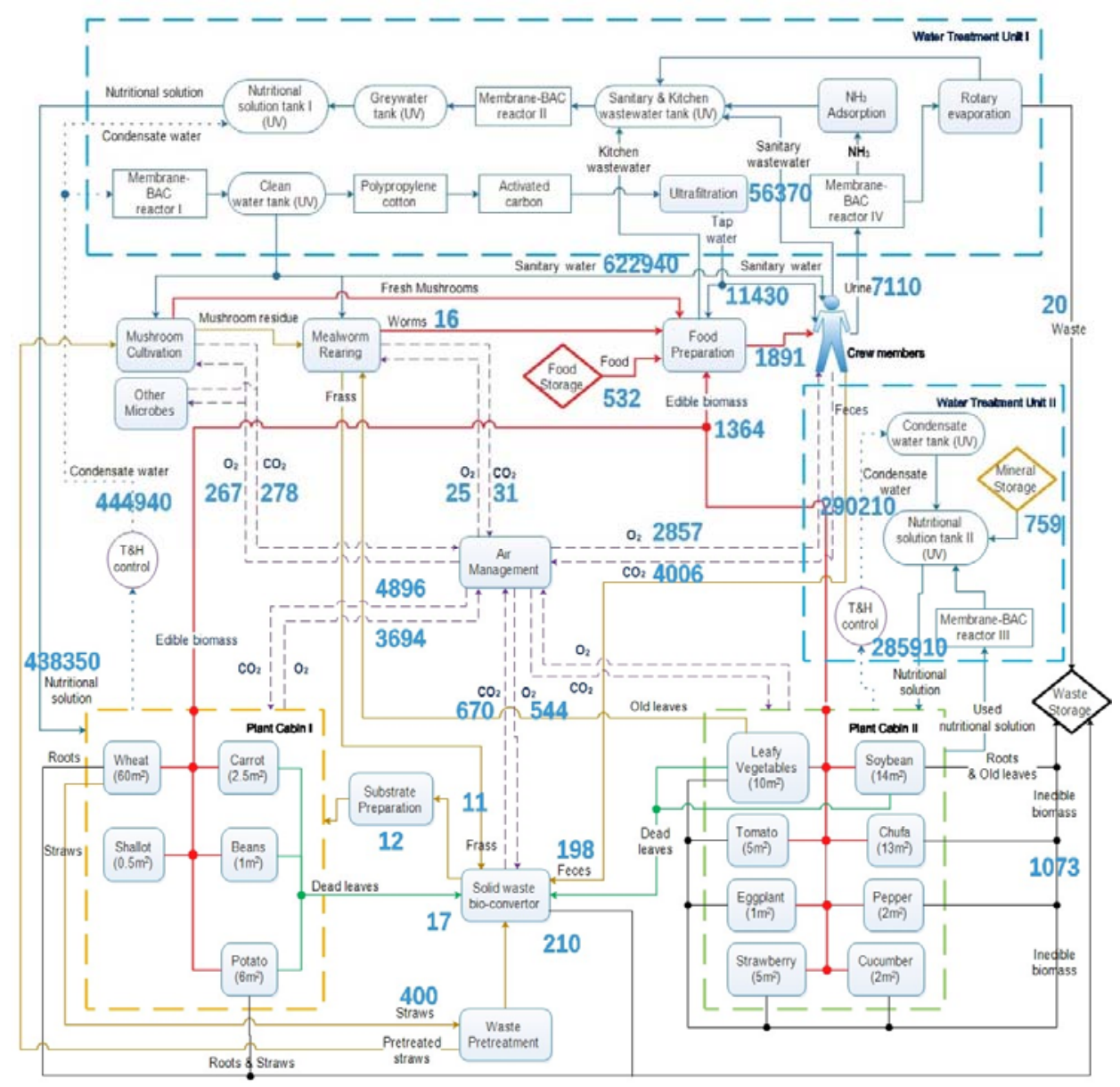

Fig. 5 Mass flow relationships among system components in the Lunar Palace 365 experiment $(\mathbf{g} / \mathbf{d})$. Arrows indicate the flow direction of mass. Object boxes represent each biological unit. The yellow, light green and blue dotted frames represent plant cabin I, plant cabin II and water treatment units. Storage waste matter, liquid, gas and food flows are marked by black, blue, purple and red arrows, respectively. The green and yellow arrows represent the cycle of solid matter. Data of solid matter was on a dry-weight basis. 
bioRxiv preprint doi: https://doi.org/10.1101/2021.01.12.426282; this version posted January 14,2021 . The copyright holder for this preprint (which was not certified by peer review) is the author/funder, who has granted bioRxiv a license to display the preprint in perpetuity. It is made available under aCC-BY-NC-ND 4.0 International license.

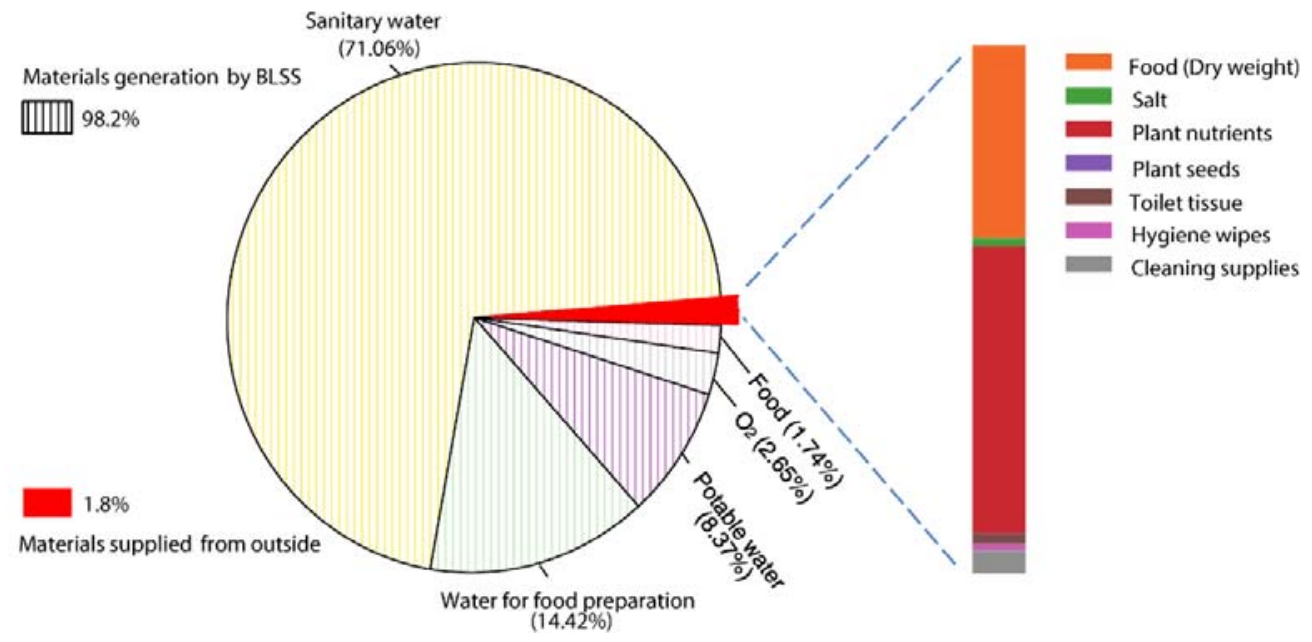

Fig. 6 The proportion of recycled substances in the total substances. 